\title{
MIGRACIONES ACTUALES EN MAGALLANES: CARACTERIZACIÓN Y TRAYECTORIAS DE NUEVOS PROCESOS MIGRATORIOS
}

\author{
DAISY MARGARIT ${ }^{a}$, WALTER IMILAN ${ }^{b} \&$ M. OLAYA GRAU
}

\begin{abstract}
RESUMEN
La provincia de Magallanes se ha transformado en la actualidad en un destino para población migrante internacional. El objetivo de este artículo es discutir las características de esta nueva migración, especialmente en la ciudad de Punta Arenas, a la luz de los procesos migratorios que experimenta Chile en años recientes, con especial foco en develar el carácter de las trayectorias migratorias que se hacen presentes en la región. Para ello se abordan cuatro dimensiones de la población inmigrante: i) características demográficas; ii) relaciones de los flujos migratorios con sus lugares de origen; iii) espacialización en la ciudad y iv) convivencia con población no migrante. La información empírica s e basa en los resultados del proyecto "Caracterización de la reciente migración extranjera en la provincia de Magallanes. Análisis socioeconómico y sociodemográfico actual”, estudio realizado en la ciudad de Punta Arenas y demandado por la Gobernación de Magallanes. La metodología empleada en el estudio fue la realización de una consulta de población, a través del análisis de fuentes secundarias, y la implementación de una encuesta dirigida a la reciente población inmigrante de origen extranjero.
\end{abstract}

PALABRAS CLAVE: migración, trayectorias migratorias, espacialidad, redes, territorio Austral.

\section{CURRENT MIGRATIONS IN MAGALLANES: CHARACTERIZATION AND TRAJECTORIES OF NEW MIGRATORY PROCESSES}

\footnotetext{
ABSTRACT

The Magallanes province has now become a destination for the international migrant population. The objective of this article is to discuss the characteristics of this new migration, especially in the city of Punta Arenas, under the light of the migration processes that Chile experiences in recent years, with special focus on revealing the character of the migratory trajectories present in the region. In order to do this, four dimensions of the immigrant population are addressed: i) demographic characteristics; ii) relations of migratory flows with their places of origin; iii) spatialization in the city

Instituto Estudios Avanzados IDEA. Universidad de Santiago de Chile. $\$ daisy.margarit@usach.cl

b Centro de Estudios Arquitectónicos, Urbanísticos y del Paisaje CEAUP, Universidad Central de Chile. walter.imilan@ucentral.cl

c Escuela Trabajo Social. Facultad de Ciencias Sociales. Pontificia Universidad Católica de Chile. Mograu@uc.cl
} 
and iv) coexistence with the non-migrant population. The empirical information is based on the results of the project "Characterization of the recent foreign migration in the province of Magallanes", a study carried out in the city of Punta Arenas and requested by the Government of Magallanes. The methodology used in the study was the realization of a population survey, through the analysis of secondary sources and the implementation of a survey aimed at the recent immigrant population of foreign origin.

KEY WORDS: migration, migration trajectories, spatiality, networks, Southern territory.

\section{INTRODUCCIÓN}

La provincia de Magallanes, específicamente la ciudad de Punta Arenas, en el extremo sur de Chile, se ha transformado en años recientes en un destino para la población inmigrante internacional. $\mathrm{Si}$ bien, Punta Arenas y Magallanes se han forjado durante el siglo $\mathrm{XX}$ en base a diversos flujos migratorios, en la última década se renueva este carácter de la región con poblaciones que son parte de flujos de migración transnacional, caracterizados por su alto dinamismo y conexión entre países vecinos. El porcentaje en Chile de población inmigrante es comparativamente bajo a nivel mundial y latinoamericano, cerca del $4,35 \%$ de la población total de acuerdo al CENSO 2017; no obstante, su distribución no es homogénea en el territorio nacional, más bien tiende a concentrarse en regiones especificas. El impacto de las nuevas poblaciones es de orden cualitativo, expresado por ejemplo en la emergencia de nuevas actividades económicas y relaciones de convivencia cotidiana en los territorios, así como la evidencia de la precariedad institucional que desemboca en la emergencia de nuevas vulnerabilidades $y$, en consecuencia, nuevas formas de exclusión y marginación (Thayer, 2016). Siguiendo a Sassen (2013) respecto de las migraciones en una escala global, aun muchas personas tratándose de residentes permanentes o de personas con ciudadanía chilena, son vistos siempre como extranjeros. En palabras de Tezanos (2006), los inmigrantes "se ven sometidos a un encadenamiento de situaciones y vivencias potencialmente exclusógenas" (p. 12), careciendo de reconocimiento de su estatus de ciudadano. Este tipo de situaciones, si bien son comunes a muchos territorios, poseen formulaciones locales que las llevan a ser experimentadas de muy diversas formas. El foco en Chile para la comprensión de la nueva migración ha estado puesto principalmente en la Región Metropolitana (de acuerdo al Censo 2017 concentra el 65,2\% de población migrate), seguido de regiones del norte del país, como Antofagasta $(8,4 \%)$ y Tarapacá $(5,9 \%)$ y algunos incipientes estudios en ciudades intermedias y pequeñas a lo largo del territorio chileno. Para el caso del extremo sur, solo contamos en la actualidad con información estadística general, proporcionada por fuentes oficiales como son el CENSO y la CASEN.

Nuestro artículo da cuenta de la inmigración actual escasamente explorada en el contexto de la Patagonia chilena. A algunos estudios clásicos, como el de Martinic (1999) sobre la migración croata, se suman otros más recientes con foco en la migración española (Cid \& Leiva, 2008) o de historias de mujeres migrantes (Angelo, 2015), todos trabajos que se centran en las poblaciones migrantes desde fines del siglo XIX y la primera mitad del XX. Las migraciones recientes en Magallanes aún no han sido problematizadas, al igual que en la Patagonia argentina donde se registran algunos trabajos más orientados a la Patagonia norte que a la zona austral (Barelli \& Dreidemie, 2015; Matossian, 2015).

El objetivo principal de este artículo es problematizar algunas de las características de la población inmigrante actual a Magallanes a la luz de los debates de la última década sobre migraciones en Chile. Abordamos cuatro dimensiones de la población inmigrante, a saber: i) características demográficas; ii) relaciones de los flujos migratorios con sus lugares de origen; iii) espacialización en la ciudad y iv) convivencia con población no migrante. De estos análisis discutimos las trayectorias migrantes de la población que participa del estudio. La información empírica se basa en los resultados de la aplicación de una encuesta a 287 individuos inmigrantes que residen en septiembre de 2015 en la provincia de Magallanes. Esta encuesta se aplicó 
en el marco del proyecto de "Caracterización de la reciente migración extranjera en la provincia de Magallanes. Análisis socioeconómico y sociodemográfico actual"1 liderado por la Gobernación de Magallanes².

Las cuatro dimensiones que se discuten en el texto participan de su propio campo de debates en la comprensión de la migración actual en Chile. Las características sociodemográficas de la población migrante varían según la región de acogida del país, mientras que en la región norte de Chile, las principales poblaciones extranjeras corresponden a nacionales de Perú y Bolivia por su cercanía territorial, en el caso de Magallanes la presencia de nacionales argentinos corresponde al colectivo más numeroso. Surgen las preguntas: ¿Qué poblaciones arriban a la región? y, en consecuencia, siguiendo los debates respecto al transnacionalismo (Levitt \& Glick Schiller, 2004), ¿qué tipo de relación establecen los inmigrantes con sus lugares de origen? En tercer término, surge como relevante comprender las formas en que la población migrante se espacializa en la ciudad, ya que estos procesos juegan un rol relevante en la revitalización de barrios y en la reproducción de redes de apoyo o, en clave negativa, pueden también alentar la estigmatización. Finalmente abordamos las relaciones de convivencia de la población inmigrante con la no-inmigrante, desde la perspectiva de los participantes del estudio.

Los hallazgos en cada una de estas cuatro dimensiones permiten analizar las trayectorias migratorias de los encuestados y con ello ampliar la comprensión y complejidad de los procesos migratorios en el país, así como el dinamismo de los territorios de destino a los que se integran con las nuevas poblaciones.

El artículo se estructura en 4 apartados: el primero da cuenta de un debate conceptual y contextual de la migración en Chile y Magallanes, el segundo aborda los aspectos metodológicos utilizados, el tercero da cuenta de los principales resultados arrojados del estudio desde las cuatro dimensiones antes señaladas y el cuarto abordará una discusión sobre las trayectorias migratorias en

1 Estudio "Caracterización de la reciente migración extranjera en la provincia de Magallanes. Análisis socioeconómico y sociodemográfico actual”. Plan 2015 Modernización Gobernaciones. Ministerio del Interior y Seguridad Pública. relación a los resultados presentados para finalizar con las conclusiones, desafíos y reflexiones finales que se desprenden del estudio realizado.

\section{LA MIGRACIÓN Y SU EXPRESIÓN EN CHILE}

La migración reciente ha sido estudiada en Chile principalmente en ciudades del norte del país y en la ciudad de Santiago (Contreras et al. 2017; Tapia, 2017, Liberona et al. 2017; Guizardi, 2016; Garcés, 2015;). La concentración y dinamismo de los flujos migrantes han llamado la atención de la investigación en diferentes campos de interés, con indagaciones en el ámbito laboral, del cuidado transnacional, de las prácticas de movilidad, entre otras. Menos conocidas son las dinámicas y características específicas de las migraciones en ciudades intermedias (Micheletti, 2016) y aún más específicamente en la zona austral.

Las migraciones internacionales han ido incrementando su relevancia como fenómeno multidimensional en Chile. A principios de la década de 1990 se constata un aumento de los movimientos migratorios entre países del hemisferio sur, por sobre todo entre países vecinos (Pedone, 2002; OIM, 2003). La desigualdad entre territorios es el principal impulsor de los movimientos migratorios, unido a inestabilidad política y crisis económicas, pero también con la disponibilidad de población joven y acceso a tecnologías de comunicación, incrementan el potencial migratorio de vastos segmentos de la población en América Latina. Los expulsores y atractores de la migración, los llamados factores push-pull por la teoría clásica, están ampliamente estudiados. Casi siempre se establece la prevalencia de la dimensión económica, y si bien siempre hay un factor de perspectiva económica presente, a éste se pliega una diversidad de factores estrechamente vinculados a las experiencias de vida de las personas, como son situaciones de violencia especialmente para el caso de mujeres.

Las características de la inmigración y sus flujos se definen según el periodo histórico y los territorios involucrados. Existe un consenso actual en señalar que la principal característica de

Punta Arenas.

2 En este estudio, los dos primeros autores del presente texto participaron en su coordinación. 
las migraciones actuales es su alto dinamismo y especificidad basada en condiciones locales de los territorios involucrados en los flujos. En efecto, los procesos de migración son específicos, son situados, aunque se observen patrones similares como en un mismo periodo histórico y sean protagonizados por colectivos del mismo origen. Por ello el estudio de los flujos de la inmigración extranjera y del impacto en los territorios se presenta como fundamental al momento de comprender la variabilidad del fenómeno, así como diseñar políticas públicas.

La migración internacional se ha constituido en un aspecto esencial de la historia de América Latina. En los últimos decenios la región se ha transformado en fuente de emigración y sus flujos la vinculan a la más amplia geografía de destinos. A comienzos de los años 2000, el contingente de migrantes ascendía a 5,9 millones de personas, lo que representaba el $1,1 \%$ de la población total de la región (OIM/Naciones Unidas). En la actualidad podemos afirmar que esta cifra que no ha descendido, de acuerdo a la información disponible, llega a casi 20 millones de latinoamericanos y caribeños que viven fuera de su país de nacimiento.

Por su parte la migración intrarregional, que acompañó las distintas etapas del desarrollo de los países de América Latina y el Caribe, históricamente ha registrado una menor intensidad. En la actualidad la denominada migración sur sur $^{3}$, caracterizada por la cercanía con el país de origen y en el que las redes sociales juegan un papel principal dentro de los factores de atracción para la nueva población migrante, en especial, a partir de la crisis europea y de Estados Unidos del 2008, dio un nuevo impulso de los flujos latinoamericanos hacia los países de la región. De este modo hoy se evidencia que "aproximadamente el 70 por ciento de toda la inmigración en la región es intrarregional. Impulsado por las disparidades económicas y del mercado laboral entre los países, la mayoría de los migrantes de la región se movilizan para trabajar" (IOM, 2018, p. 80).

3 Los sujetos migrantes sur-sur revisten importancia económica por la magnitud de las cifras y la escala potencial de las remesas, pero sus experiencias son un ámbito que prácticamente no ha sido objeto de estudio. Ese desconocimiento por parte de los encargados de la

\section{Chile, un destino migratorio}

La inmigración extranjera que ha llegado a Chile en este último periodo se ha caracterizado principalmente por provenir de países latinoamericanos, por su heterogeneidad étnica, perteneciente a un rango etario activo en términos laborales y por ser mayoritariamente femenina. Estos flujos han crecido de forma sostenida (Margarit \& Bijit, 2014).

La información de caracterización de la inmigración en Chile aún es deficiente. Se trata de bases de datos sectoriales y discontinuas en términos temporales como es el caso del Censo en los últimos años. Una fuente relevante para el diseño de políticas públicas es la Encuesta de Caracterización Socioeconómica Nacional (CASEN), que se realiza cada dos años e incorpora algunas preguntas sobre migración, lo cual nos permite conocer ciertas tendencias en los flujos migratorios y sus transformaciones en periodos más cortos de tiempo. Por último, los registros de entrada y salida de extranjeros del país aportan solo desde la dimensión de la movilidad de personas en frontera.

Pese a estas dificultades para caracterizar el dinamismo de las poblaciones migrantes en Chile, de acuerdo con las cifras del Censo de población del año 2017, en nuestro país residían 745.772 personas nacidas en el extranjero, representando al $4,35 \%$ del total de población. De esta cifra, el $72,9 \%$ corresponde a inmigrantes sudamericanos, siendo el principal colectivo extranjero el peruano con un $25,26 \%$, la población colombiana con un $14,1 \%$, la venezolana con un $11,1 \%$, la boliviana con un $9,9 \%$, la argentina con un $8,9 \%$ y en menor número encontramos a nacionales ecuatorianos con un $3,7 \%$, entre otros. Del resto del mundo están presentes europeos, norteamericanos y asiáticos con un $13 \%$ de representatividad.

De acuerdo a los datos arrojados desde el INE y el Departamento de Extranjería y Migración 18 meses después del último Censo oficial (INE, 2018), se estima que la población extranjera en

formulación de políticas refleja, en gran medida, la falta de datos fiables sobre los migrantes que se desplazan de un país a otro, pero también el predominio de las corrientes migratorias sur-norte en los debates normativos y en la investigación (OIM, 2014). 
el país asciende a 1.251.225 personas, lo que representa el $7 \%$ de la población total. De este porcentaje, el $71 \%$ corresponde a inmigración sudamericana. Dentro de este grupo destaca la población de origen venezolano que concentra el $23 \%$, desplazando a las poblaciones de origen fronterizo, como la peruana (18\%), la cual mantuvo más representatividad hasta el Censo 2017 con un $25,2 \%$. A lo anterior se suma un nuevo colectivo que alcanza un importante porcentaje de representatividad como es la población proveniente de Haití, 14,4\%, la cual de acuerdo a los datos entregados por la Encuesta de Caracterización Socioeconómica Nacional (2015) indicaba que la población inmigrante de origen haitiano alcanzaba el 2,9\%, dado cuenta si del dinamismo del fenómeno migratorio.

La inmigración actual en Chile, que se inicia en la década de 1990, se suele indicar como una "nueva migración" (Stefoni, 2011). La novedad de este movimiento de personas subyace en tres características fundamentales. La primera referida al tipo de proyecto migratorio sostenido bajo la denominación amplia de migración transnacional (Levitt \& Glick Schiller, 2004) que plantea que las personas que migran mantienen un contacto permanente con "los que se han quedado". De esta manera se trataría de poblaciones que mantienen relaciones de "ida y vuelta" con sus lugares de origen. Una segunda característica de la migración actual son los países de origen, principalmente de los tres países vecinos a Chile y, más recientemente, de la región del Caribe: Colombia, República Dominicana, Venezuela y Haití. Cabe destacar que un ejemplo del alto dinamismo de los flujos migrantes se expresa en el crecimiento reciente de dos colectivos que hasta hace poco tenían un peso menor en los flujos migratorios: Haití y Venezuela. Ciudadanos de estos países que solicitaron visa de residencia el 2013 fueron 2.499 haitianos y 1.552 venezolanos, el 2017 se elevaron a 23.095 y 32.089 respectivamente ${ }^{4}$. Este tipo de variaciones parece ser común más que excepcional en el contexto de las actuales migraciones. Una tercera característica dice relación con la llamada "feminización", es decir, la mayor presencia de

4 Según Departamento de Extranjería, visitado el 20 de marzo de 2018

5 Estudio de Caracterización de la reciente migración mujeres por sobre hombres, lo que ha dado origen a una serie de fenómenos desconocidos en flujos migratorios anteriores, como es un mercado del trabajo para trabajos "feminizados" de la migración y transformaciones en las concepciones de familiar y cadenas de cuidado (Irazábal, 2013).

\section{Migración reciente en la región de Magallanes}

La región de Magallanes es autopercibida por sus habitantes como un espacio de movilidad transnacional, especialmente por su historia de colonización y la relación con la Patagonia argentina; no obstante, la presencia inmigrante contemporánea cambia la idea de migración al tener su origen en países de la región del Caribe.

Según el Censo del año 2017, en la Región de Magallanes y la Antártica Chilena residian 4.714 extranjeros. De dicha cifra, el $61,2 \%$ de los migrantes es de origen latinoamericano, principalmente argentinos, representando al $36,4 \%$ del total de la población extranjera.

Lo anterior se condice con los datos arrojados por la CASEN 2017, que registra un $3,7 \%$ de inmigrantes residentes en la región de Magallanes. De acuerdo a las nacionalidades con mayor porcentaje, se destaca Argentina, República Dominicana, Perú y Colombia como los 4 países de origen con mayor presencia en la región.

La región norte de Chile es considerada como una zona transfronteriza (Tapia \& González, 2014), de forma similar, Magallanes también es un territorio cotidianamente vinculado a la Patagonia argentina a través de una frontera "porosa" en los intercambios de objetos y movimientos de poblaciones de forma temporal. El arribo de nacionales colombianos y dominicanos abre una nueva faceta esta concepción de lo transfronterizo, permitiendo la generación de vínculos transnacionales más allá de la contigüidad físico espacial de la frontera chileno-argentina.

A partir de los resultados empíricos del estudio que llevamos a cabo en la provincia de Magallanes ${ }^{5}$ emergieron las tres características centrales con las que se definen las migraciones actuales. Por un lado, se aprecia una presencia

extranjera en la provincia de Magallanes. Análisis socioeconómico y sociodemográfico actual (2015). 
reciente de migrantes latinoamericanos con un fuerte componente femenino. A estos flujos se suman los que se han producido históricamente entre Chile y Argentina, no obstante, es importante notar que se trata de dinámicas diferentes, respondiendo a procesos de inserción y tipos de proyectos migratorios diferenciados.

Por tanto, el fenómeno de la migración en Magallanes, si bien no es un fenómeno nuevo en la región, en la actualidad adquiere particularidades que lo hacen distinto tanto por el origen de las poblaciones de inmigrantes, como por las condiciones sociales y culturales que adquiere hoy en día la sociedad receptora. Por ello y a partir del estudio sobre la situación migratoria en Punta Arenas (2015), en la actualidad se pueden reconocer tres tipos de migraciones que conviven en el territorio magallánico:

a) Migración histórica: Corresponde a la población descendiente de colonos de fines del siglo XIX y principios del XX. Entre ellos se encuentra la población de origen balcánico y europeo en general que ya se encuentra en segunda y tercera generación. Dentro de la migración histórica destaca la población de origen argentino, que ininterrumpidamente se ha movido desde un país al otro, dando vida a una dinámica de tipo transfronteriza (Tapia \& González, 2014). Estos segmentos poblaciones responden a dinámicas muy diferentes, sin embargo, ambos son considerados como población "local" por los años de inserción en la sociedad magallánica.

b) Migración calificada: Respondería a un segundo tipo de migración, el cual ha experimentado un mayor incremento en el último periodo. Se caracteriza por personas con altos niveles de educación y calificación laboral. En este grupo se reconocen profesionales y técnicos especializados que se insertan en la provincia de Magallanes en trabajos bien remunerados $y$ con relativa estabilidad, en general vinculados a economías de tipo extractivistas. Dentro de este segmento se pueden identificar dos tipos de poblaciones, cuyo principio de distinción se basa en su participación en la vida cotidiana de la sociedad magallánica.

En un primer segmento, cabe destacar que algunos empleos en los que se concentra este tipo de población se desarrollan bajo dinámicas de enclave, que inhibe que este segmento de trabajadores se inserte en la cotidianeidad de la provincia de Magallanes. En estos términos, es una población relativamente invisible como segmento migrante para la comunidad local.

También se identifica otro segmento de profesionales que experimenta una situación muy distinta respecto a su visibilidad. Se trata de profesionales en el ámbito de la salud con trabajo en consultorios de atención primaria, estableciendo una relación directa con la comunidad.

c) Migración basada en redes para su inserción: Un tercer tipo de migración corresponde a una población de reciente arribo, proveniente de países latinoamericanos; sus proyectos migratorios están fuertemente sustentados en redes de apoyo para lograr inserción en trabajos de baja remuneración y precarias condiciones laborales.

\section{ASPECTOS METODOLÓGICOS}

La metodología empleada en el estudio fue la realización de una consulta de población, que se desarrolló en 4 etapas. La primera etapa consistió en realizar el análisis de información disponible, a través de fuentes secundarias emanadas principalmente de instituciones públicas. Durante la segunda etapa se levantó una encuesta y se llevó a cabo una Consulta Migrante, para dar paso a la tercera etapa de análisis de las encuestas y, por último, la presentación de los resultados. Estas etapas se especifican a continuación:

En la Etapa 1 se realizó un análisis de información disponible, donde se revisaron bases de datos nacionales. Las cifras se desagregaron a nivel de provincia de Magallanes. Las fuentes analizadas fueron las siguientes: i) CASEN 2013, 
Ministerio de Desarrollo Social; ii) Ficha Protección Social, 2013, Ministerio de Desarrollo Social; iii) CENSO 2002 y iv) Cifras de visas, Departamento de Extranjería. También se realizaron reuniones y entrevistas con profesional técnico y directivos de distintos servicios públicos para recolectar información de antecedentes de la población migrante. Estas reuniones se llevaron a cabo con funcionarios de la Dirección Regional del Instituto Nacional de Estadísticas, de la Seremi del Ministerio de Desarrollo Social, funcionarios de la Policía de Investigaciones, Corporación Municipal de Salud, e investigadores y consultores regionales, entre otros actores relevantes.

La Etapa 2 se centró en la preparación y aplicación de la encuesta de caracterización sociodemográfica llamada Consulta Migrante. En un primer momento, se realizó el diseño de la encuesta, a través de la identificación de un set de variables a consultar. Este set fue consensuado con la contraparte técnica del estudio y abordó las siguientes temáticas: i) Datos sociodemográficos de la muestra; ii) Residencia en Chile y situación migratoria; iii) Vínculos con su país de origen y remesas; Iv) Familia; v) Vivienda; vi) Trabajo; vii) Redes y discriminación; viii) Servicios y ix) Proyección y sentimiento magallánico. Cabe señalar que esta encuesta fue validada y piloteada previamente a su aplicación final, lo que implicó reformular el instrumento.

A partir de ahí, se realizó una campaña de promoción de encuesta ${ }^{6}$ para luego concretar su aplicación. Se aplicó un total de 287 encuestas, de las cuales fueron validadas 266. La aplicación de la encuesta tuvo una duración promedio de 26 minutos. La participación de las personas fue voluntaria, autodeclarativa de su situación migratoria y anónima.

Cabe destacar que con un importante número de personas consultadas fue posible generar una situación de entrevista semiestructurada con los participantes. En estos contextos conversacionales surgieron elementos significativos para el análisis de los datos recolectados, así como proveyeron antecedentes complementarios para la comprensión, especialmente, de las trayectorias

6 Esta fase contempló una serie de actividades de vinculación con instituciones locales y de promoción, a través de instituciones públicas y medios de comunicación, de la migrantes. La información que surgió de estos episodios fue sistematizada para apoyar la etapa de análisis.

Durante la Etapa 3 se realizó el análisis descriptivo de los resultados arrojados por las entrevistas semiestructuradas. El análisis de la encuesta lo llevó a cabo un equipo de especialistas en análisis de datos cuantitativos, realizando análisis descriptivos de las variables consultadas y los datos obtenidos. Este estudio se ejecutó a través de la plataforma Survey Pocket (c) junto a SPSS (C). Adicionalmente se desarrolló una georeferenciación de datos relevantes a través del software ArcGis ${ }^{\circledR}$, de este modo se identificó la expresión espacial de dichos datos, tales como concentración residencial y proveniencia de los consultados, las cuales se exponen en el desarrollo de este informe.

Por último, en la Etapa 4 y final, se realizó la presentación de resultados que se llevó a cabo a través de tres actividades (seminario, curso y taller) realizadas con la colaboración de las Universidades de Magallanes y Central de Chile junto a la Gobernación de Magallanes. Para ello se organizó un curso, taller y seminario en conjunto, cuyo objetivo principal fue transferir conocimiento en torno a la migración internacional reciente en la provincia de Magallanes y su relación con los servicios públicos.

A partir de los datos del estudio se realizó un análisis de segundo orden que contempló de un modo secuencial, en el sentido que señala Morse (2003), el uso de información cuantitativa y cualitativa (entrevistas semiestructuradas a sujetos migrantes y a informantes calificados), que posteriormente se validó a partir de una triangulación de la información con una reflexión teórica acerca de las trayectorias migratorias.

\section{PRINCIPALES RESULTADOS}

Los principales resultados del proceso de investigación se han sintetizado en 4 dimensiones, a saber: características sociodemográficas, relaciones con sus lugares de origen, espacialización en la ciudad y convivencia con población no migrante.

realización de la consulta. Se generó material gráfico como posters y flyers. 
Una vez descritas estas dimensiones, se focalizará la reflexión en las trayectorias migratorias comprendidas desde la aproximación de Lacomba, como "el tránsito de un espacio social, económico, político y/o cultural a otro, con el fin de desarrollar un determinado proyecto y tratar de responder a ciertas expectativas personales o de grupo" (Lacomba, 2001. Citado en Garcés 2014). En este sentido, como señala Garcés (2015), "esta definición amplía el concepto de movimiento que hay entre territorios que son comunicados a través de la población que se desplaza" (Garcés, 2015, p. 185).

\section{Características sociodemográficas}

La muestra se divide en $61 \%$ de sexo femenino y 39\% masculino. La Fig. 1 muestra los porcentajes de personas consultadas según nacionalidad. Los consultados, en mayor número, son ciudadanos colombianos (28\%), seguido de argentinos (23\%) y luego dominicanos (12\%). La categoría 'Otra' incluye inmigrantes provenientes de Cuba, México, Alemania, India, Corea, Francia, Italia, Indonesia, Polonia, Panamá, Portugal y Rusia.

En la Fig. 2 se distribuyen las diferentes nacionalidades entre hombres y mujeres. Existe mayor predominancia de mujeres encuestadas de origen dominicano, paraguayo, brasileño, ecuatoriano, colombiano y peruano. Los hombres que predominan son argentinos, venezolanos $y$ españoles.

\begin{tabular}{r|c} 
Colombiana & \multicolumn{2}{|c}{$28 \%$} \\
Argentina & \multicolumn{2}{|c}{$23 \%$} \\
Dominicana & $12 \%$ \\
Peruana & $8 \%$ \\
Otra & $8 \%$ \\
Paraguaya & $6 \%$ \\
Venezolana & $5 \%$ \\
Uruguaya & $3 \%$ \\
Brasileña & $2 \%$ \\
Ecuatoriana & $2 \%$ \\
Española & $2 \%$ \\
Estadounidense & $1 \%$
\end{tabular}

Fig. 1. Nacionalidades

Fuente: Elaboración propia a partir de Encuesta Consulta Migrante de Magallanes 2015.

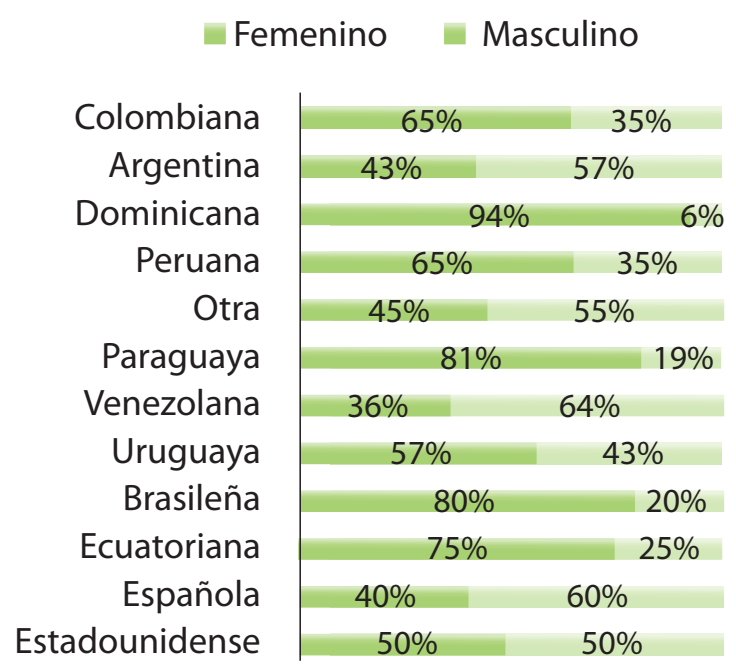

Fig. 2. Nacionalidades según sexo

Fuente: Elaboración propia a partir de Encuesta Consulta Migrante de Magallanes 2015.

La edad de los consultados promedia en los 34 años. En el caso de los colectivos colombianos y dominicanos, poseen un mayor porcentaje relativo de población menor de 30 años. Casi la totalidad de los encuestados aseguró que su idioma materno es el español (90\%). El 100\% de los consultados tiene dominio del habla española, un $93 \%$ domina la lectura y un $89 \%$ la escritura. En términos de estudios formales, la mayor concentración se encuentra en la categoría "Educación secundaria completa" con un $31 \%$, luego el $28 \%$ de los consultados tiene como último nivel terminado "Educación universitaria completa". La Fig. 3 muestra estos porcentajes y

\begin{tabular}{r|cc} 
No cuenta con estudios & $0 \%$ \\
Educación primaria incompleta & $4 \%$ \\
Educación primaria completa & $7 \%$ \\
Educación secundaria ... & $9 \%$ & $31 \%$ \\
Educación secundaria completa & \multicolumn{2}{|c}{$3 \%$} \\
Educación técnica incompleta & $2 \%$ & \\
Educación técnica completa & $9 \%$ \\
Educación universitaria ... & $10 \%$ \\
Educación universitaria ... & \multicolumn{2}{|c}{$28 \%$}
\end{tabular}

Fig.3: Nivel educacional terminado

Fuente: Elaboración propia a partir de Encuesta Consulta Migrante de Magallanes 2015. 
Educación primaria

Educación secundaria

Educación técnica

Educación universitaria

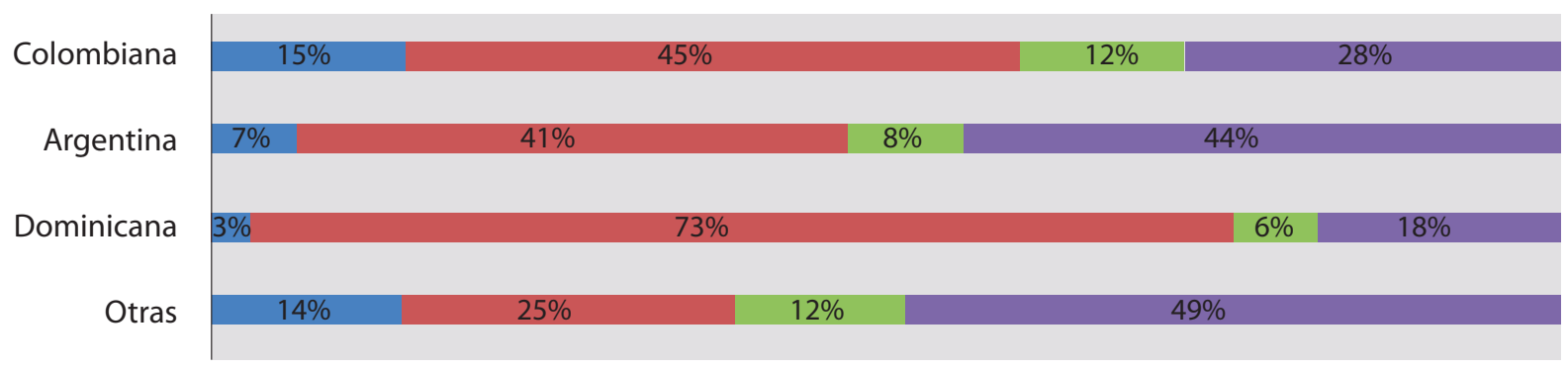

Fig.4. Nacionalidades más comunes según nivel educacional

Fuente: Elaboración propia a partir de Encuesta Consulta Migrante de Magallanes 2015.

la distribución de los demás niveles educacionales terminados. Solo el 6\% de los consultados cursó el último nivel de estudios en Chile.

Por otro lado, solo el $28 \%$ ha convalidado $y / u$ homologado sus estudios en Chile. De las personas encuestadas solo el $6 \%$ actualmente está estudiando $y$ este $6 \%$ se distribuye equitativamente entre educación secundaria, técnica y universitaria, con $2 \%$ de encuestados en cada una de las categorías.

Finalmente, se analiza la distribución del nivel educacional en las nacionalidades más comunes (Fig. 4). Un alto porcentaje de colombianos tiene un nivel de escolaridad secundaria (45\%), seguido por un $28 \%$ con educación universitaria. De los argentinos consultados el $44 \%$ tiene educación universitaria. En el caso de los dominicanos, un gran porcentaje cumple con educación secundaria (73\%), teniendo el promedio más bajo de escolaridad entre los países comparados. Por último, la categoría "otras nacionalidades" tiene el mayor porcentaje de consultados con alto nivel educacional, el $49 \%$ asegura tener educación universitaria.

La Fig. 5 muestra los años que llevan viviendo en Chile las personas consultadas. La mayor cantidad se encuentra entre menos de 1 año y 1 año (18 y 19\% respectivamente). Luego la gráfica va decayendo al subir el número de años. Esto quiere decir que, del total de personas consultadas, la gran mayoría ha llegado a Chile en los últimos 5 años. Existe un $4 \%$ que no está graficado y que corresponde a las personas que han vivido en varios periodos distintos.

En la Fig. 6 se desagrega esta información por nacionalidad, mostrando que los colectivos de más reciente arribo a Chile son los dominicanos y colombianos.

El ingreso de los inmigrantes a Magallanes se produce en un $26 \%$ por los pasos fronterizos terrestres (mayoritariamente por el paso Integración Austral o ex Monte Aymond), siendo el 58\% de ellos de nacionalidad argentina. Cabe destacar que el $8 \%$ ingresó por la región de Arica y Parinacota, siendo el $86 \%$ de ellos colombianos.

Las razones por las cuales los encuestados declaran haber venido a Chile se observan en la Fig. 7. De las personas encuestadas, 133 de ellas llegaron a Chile por temas relacionados al trabajo, luego 41 consultados por reunificación familiar y otros 41 por vínculos amorosos. Es importante

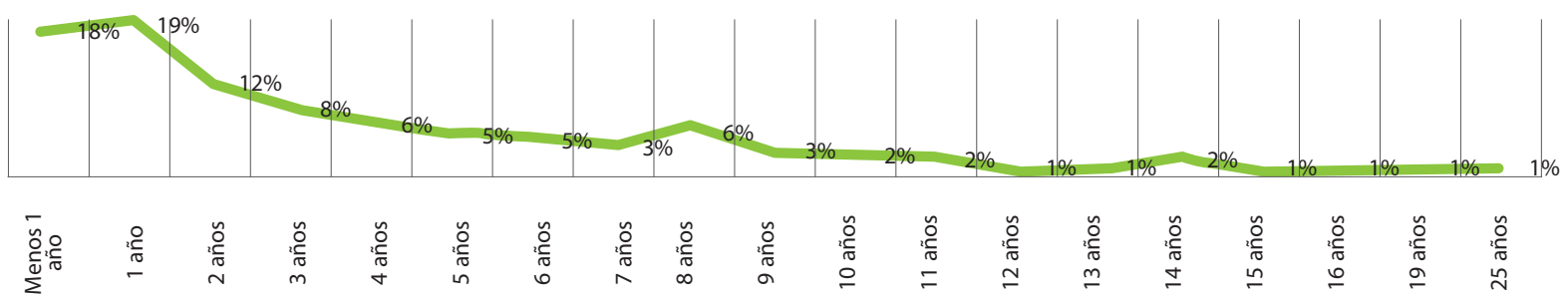

Fig. 5. Años viviendo en Chile

Fuente: Elaboración propia a partir de Encuesta Consulta Migrante de Magallanes 2015. 


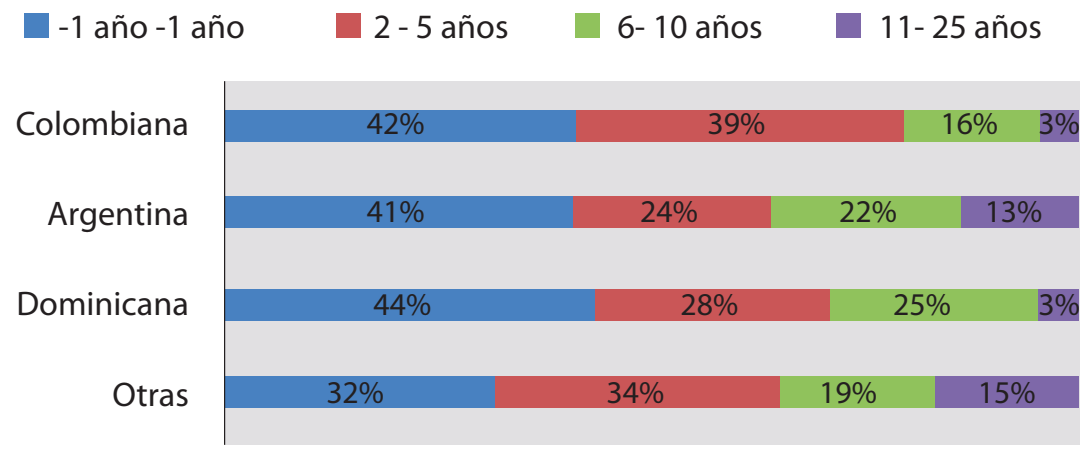

Fig. 6. Nacionalidaes más comunes según años viviendo en Chile

Fuente: Elaboración propia a partir de Encuesta Consulta Migrante de Magallanes 2015.

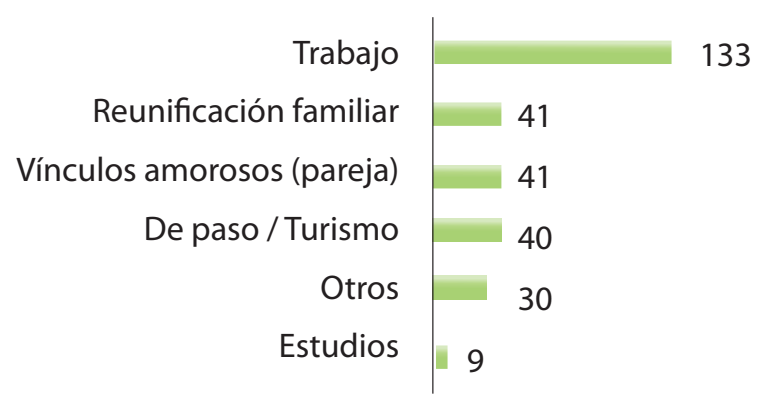

Fig. 7. Frecuencia de motivo para venir a Chile Fuente: Elaboración propia a partir de Encuesta Consulta Migrante de Magallanes 2015.

considerar que las personas podrían tener más de una razón para venir a Chile, es por eso que se obtuvo un total de 294 motivos, a pesar de que fueran 266 el total de encuestados.

Con respecto al estado de la visa de los consultados, el $72 \%$ tiene visa y solo un $2 \%$ no tiene. El $12 \%$ de las personas la está tramitando por primera vez y el $9 \%$ la está renovando. Solo el 5\% tiene doble nacionalidad. Los consultados que declaran no tener visa se debe a que no han hecho los trámites necesarios, la distancia de Punta Arenas, porque no le dio importancia, pérdida de documentos y por no tener trabajo. La Fig. 8 muestra los diferentes tipos de visa por nacionalidad.

De aquellas personas que tienen visa o la están tramitando o renovando, éstas se distribuyen entre Residencia definitiva (45\%), visa temporaria (39\%), sujeta a contrato (12\%) y de turismo (3\%).

\section{Relaciones con sus lugares de origen}

En esta dimensión se analiza los lazos inmigrantes con su país de origen mediante los diferentes mecanismos de comunicación, tales como pueden ser compartir información que permite mantener la cadena migratoria, sostener vínculos afectivos así como envíos de remesas. Por

\section{Colombiana $\quad$ Argentina Dominicana $\square$ Otras}

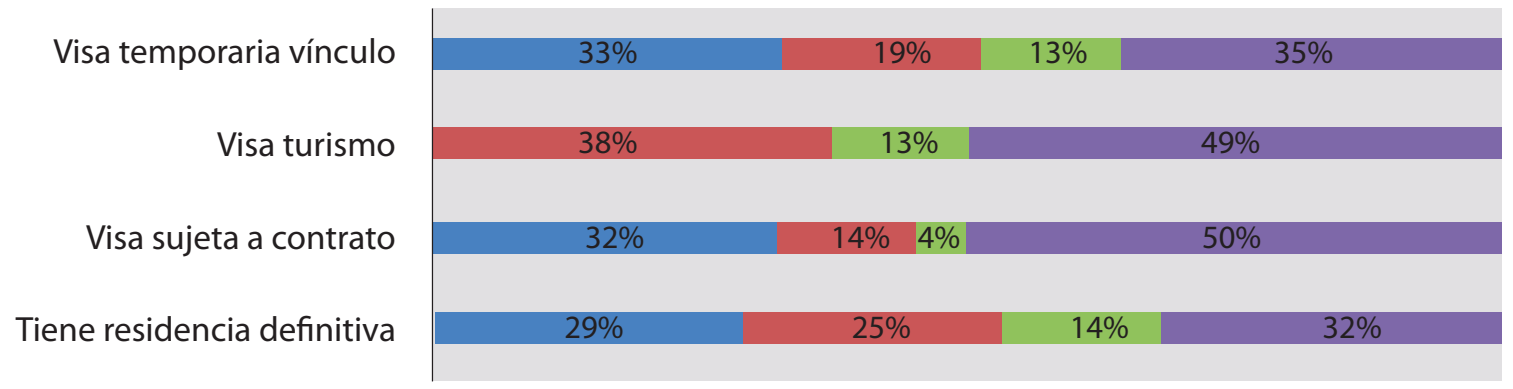

Fig. 8. Tipo de Visas según nacionalidades

Fuente: Elaboración propia a partir de Encuesta Consulta Migrante de Magallanes 2015. 


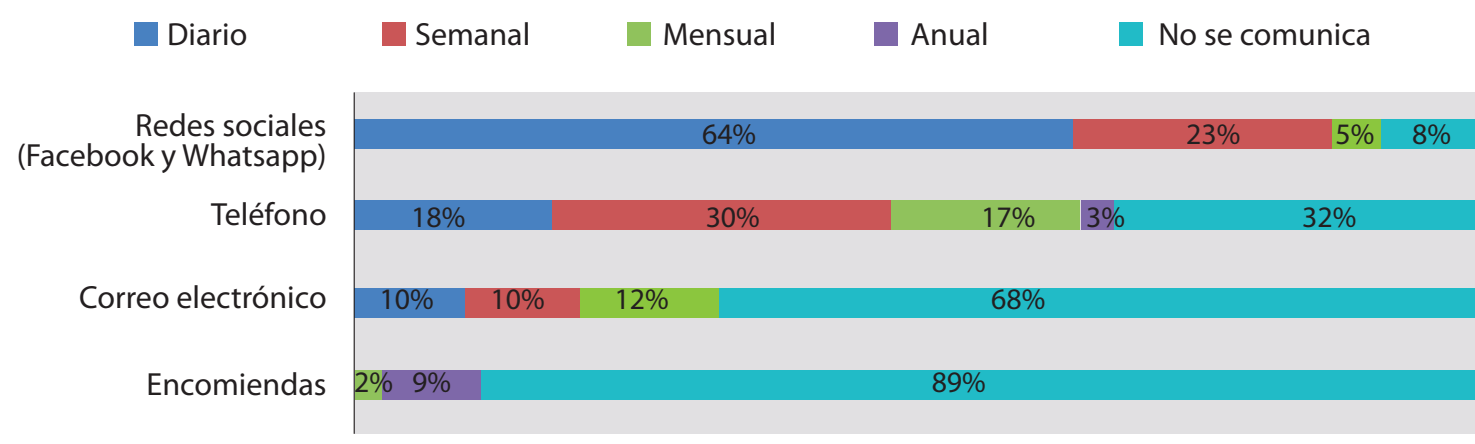

Fig. 9. Formas de comunicación de extranjeros y su país de origen según periodicidad

Fuente: Elaboración propia a partir de Encuesta Consulta Migrante de Magallanes 2015.

medio de estas conexiones no solo las personas logran construir una espacialidad transfronteriza a través de los distintos elementos que fluyen, sino también los territorios distantes en términos físicos se conectan, generando una interdependencia entre ellos.

De los encuestados, el $65 \%$ ha visitado su país de origen desde que se encuentra en Chile. De este grupo, el $50 \%$ ha ido a su país al menos 3 veces. Del total de encuestados que asegura haber visitado su país de origen desde que vive en Magallanes se obtiene un promedio de 7,7 viajes al país de origen.

Junto a los viajes presenciales, existen diversas formas en las que los inmigrantes se comunican con su país de origen, como es a través de redes sociales o en el envío de objetos. En la Fig. 9 se presenta que la manera más cotidiana de comunicarse es mediante las redes sociales, un $64 \%$ de los encuestados declara utilizar estos medios de forma diaria y un $23 \%$ lo utiliza semanalmente. La llamada telefónica se usa con frecuencia, pero en menor medida que las redes sociales. El correo electrónico y finalmente las encomiendas casi no son utilizados.

En relación con las remesas, la Fig. 10 nos muestra que el $45 \%$ no envía nunca dinero fuera de Chile. Un 37\% lo hace al menos una vez al mes y un $11 \%$ lo realiza de forma muy ocasional. En total 145 consultados sí envía dinero, independiente de su periodicidad. Dentro de los que envían dinero de forma mensual el $47 \%$ es colombiano, $25 \%$ dominicano y $24 \%$ de otra nacionalidad.

En cuanto al uso que se entrega al dinero enviado por las 145 personas, 69 consultados lo envía para el cuidado de sus padres, 48 para el cuidado de sus hijos y 48 más con otro motivo. $\mathrm{Si}$ bien, las remesas pueden tener múltiples propósitos, destacan como las principales las que dicen relación con las cadenas de cuidado.

Del total de personas que sí envía dinero fuera del país, el $43 \%$ envía una parte muy pequeña de su dinero, el 25\% menos de la mitad de su dinero, el $19 \%$ la mitad, el $12 \%$ más de la mitad o casi todo. En Chile no existen estudios sobre el envío de remesas de la población inmigrante, por lo que no se puede establecer si estos montos $y$ regularidades en términos cuantitativos son

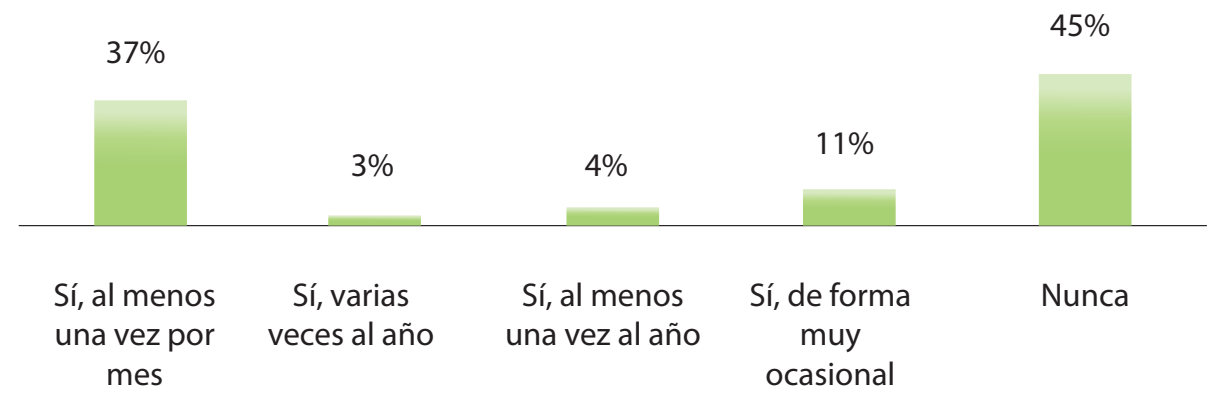

Fig. 10. Frecuencia con la que envía dinero fuera del país

Fuente: Elaboración propia a partir de Encuesta Consulta Migrante de Magallanes 2015. 
significativos o no. En nuestro estudio destaca, no obstante, que al menos un cuarto de la población encuestada envía un porcentaje importante de sus ingresos generados en Chile a sus familias que han quedado en sus lugares de origen.

\section{Espacialización en la ciudad}

Los primeros estudios de inmigración y espacialización en la ciudad mostraban la concentración de colectivos migrantes en áreas centrales. Tomado como regla general, pocas veces se tomaba atención que la evidencia empírica provenía de ciudades estadounidenses de la primera mitad del siglo XX (Whyte, 1943; Park, 1999). Los primeros estudios de análisis espacial de la población migrante en ciudades chilenas, básicamente localizados en Santiago, observan la concentración de población migrante en comunas del centro de la ciudad, haciendo uso de una serie de infraestructuras y servicios disponibles y de un stock disponible de viviendas, en general en condiciones de deterioro (Ducci \& Rojas, 2010; Garcés, 2012). La situación ha cambiado en la ciudad de Santiago, desde esta concentración inicial durante la primera década del presente siglo, la población migrante ha tendido a localizarse en áreas peri-centrales e incluso periféricas (Imilan et al. 2016). Si bien aún no contamos con estudios focalizados sobre estas dinámicas, en términos cualitativos se ha observado que la consolidación de proyectos migratorios permite a los migrantes acceder a redes más amplias y, en consecuencia, lograr un acceso a viviendas más adecuadas a sus necesidades cotidianas de organización de acceso laboral y cadenas de cuidado. Para el caso de ciudades intermedias, solo algunas pocas publicaciones plantean dinámicas de acceso a vivienda, como es el caso de Iquique donde se ha generado una concentración en el centro histórico de la ciudad (Contreras \& Palma, 2015). La información que se construye a partir de la Consulta Migrante de Magallanes es una primera aproximación de las formas de territorialización de la migración actual en Punta Arenas.

La Fig. 11 muestra la espacialización de las residencias de los participantes de la Consulta a través de un mapa de Punta Arenas que destaca

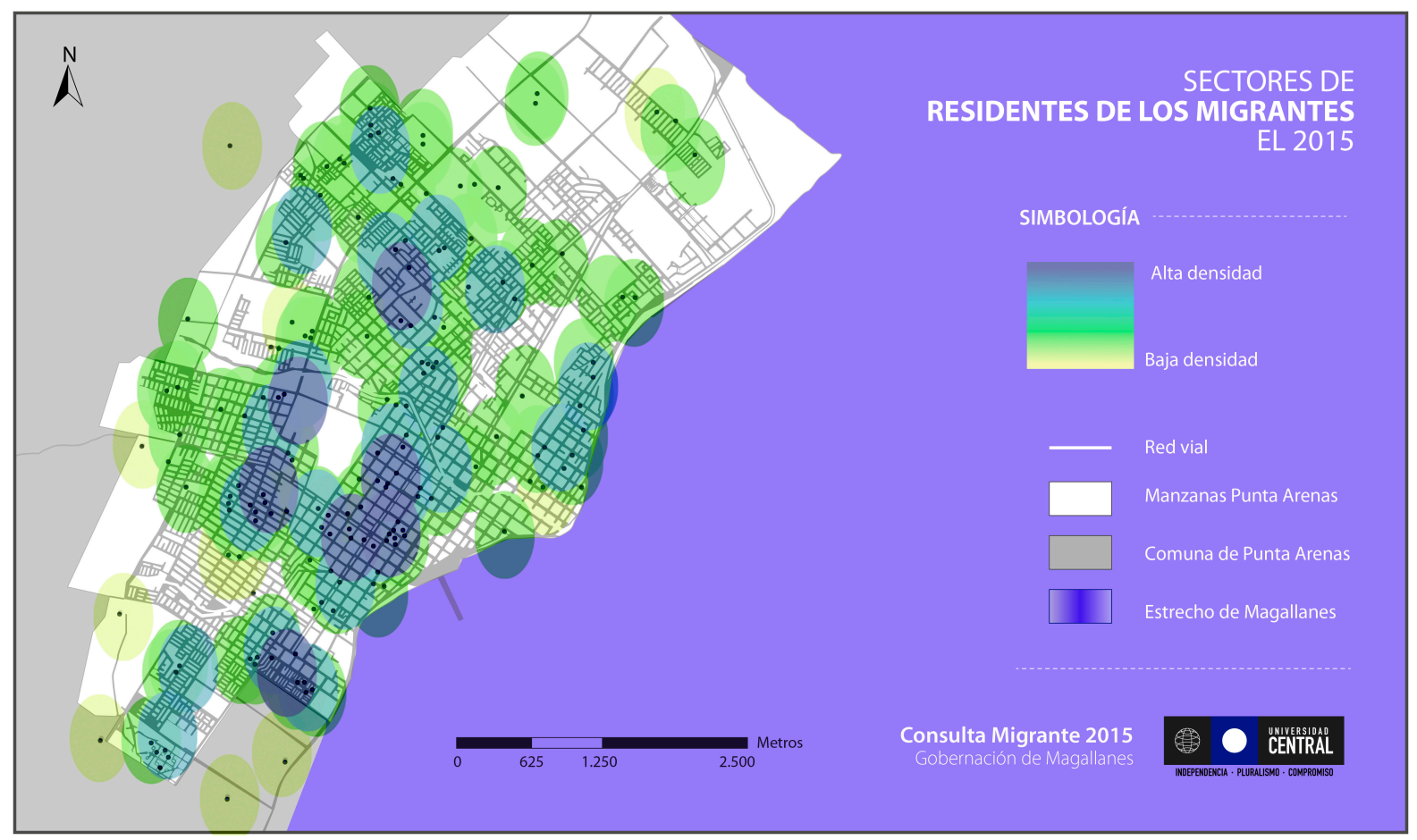

Fig. 11. Residencia Migrantes 2015

Fuente: Elaboración propia a partir de Encuesta Consulta Migrante de Magallanes 2015. 


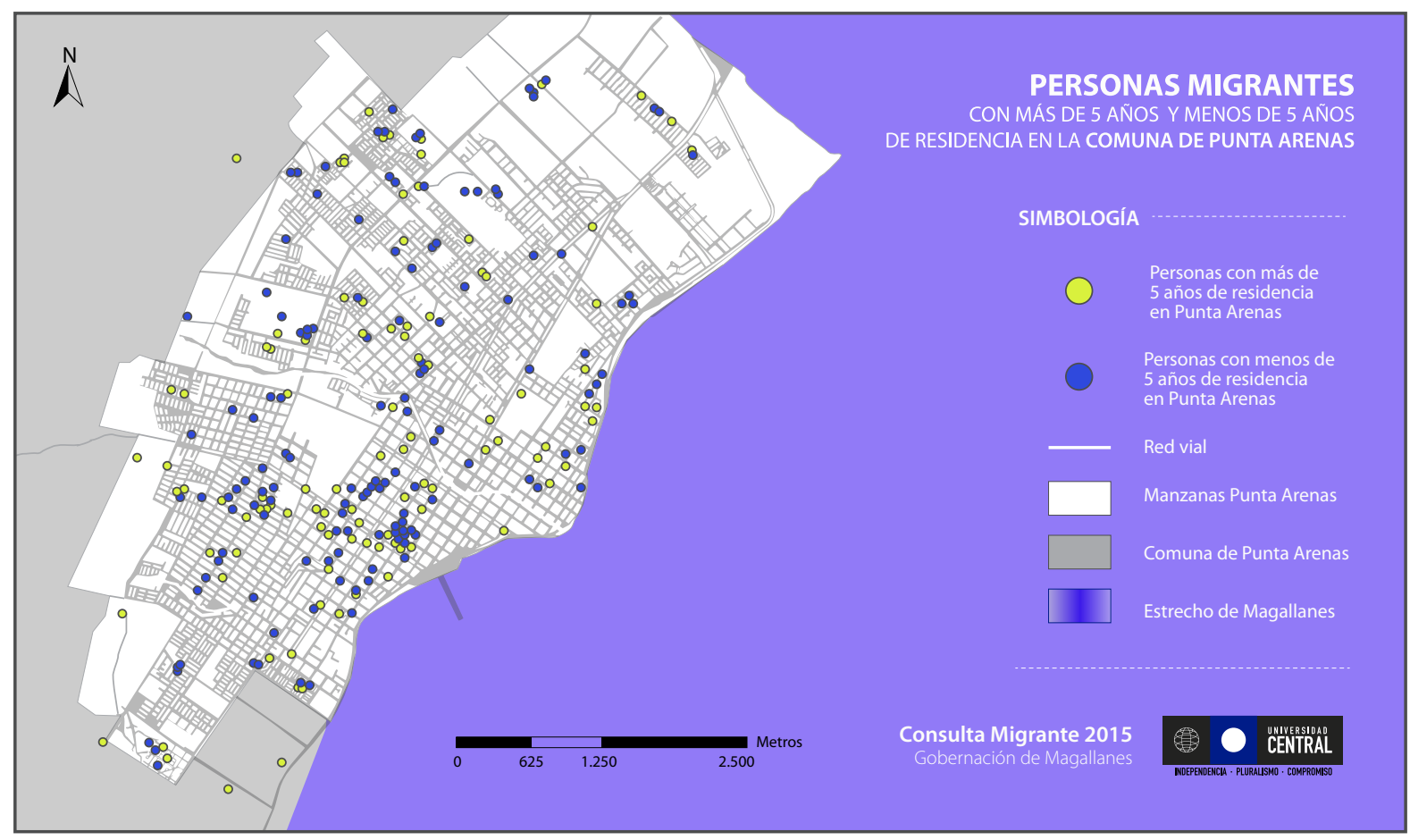

Fig. 12. Migrantes con más de 5 años y menos de 5 años de residencia en Punta Arenas Fuente: Elaboración propia a partir de Encuesta Consulta Migrante de Magallanes 2015.

las densidades de concentración de la población migrante. Se aprecia una leve concentración en torno al centro administrativo de la ciudad, justamente donde se encuentran edificaciones antiguas y de un tamaño superior al promedio de aquélla. Este stock de viviendas permite el acceso a arriendo de piezas y la conformación de viviendas colectivas. No obstante, destaca de la cartografía una distribución de la población migrante por diferentes barrios dispersos por la ciudad.

La Fig. 12 muestra las residencias de los consultados distinguiendo entre las personas que tienen menos de 5 años en Magallanes y las que tienen más de 5 años. Esta distinción se basa en la observación empírica de cinco años, si bien arbitraria es metodológicamente relevante para fijar una frontera en la consolidación de los proyectos migratorios (Imilan et al. 2016). Según lo observado en Santiago, alrededor de cinco años se requieren para consolidar un proyecto migratorio, expresado en las trayectorias laborales que repuntan una vez que han experimentado una baja en los primeros años, una expansión de redes de apoyo y de información que incrementa los recursos de inserción de los migrantes y junto a ello, una mayor estabilidad en los ingresos. En función de esta distinción se aprecia que las residencias de la población migrante no varían dependiendo de la consolidación de los proyectos migratorios. Esto llevaría a hipotetizar que las áreas de la ciudad donde se insertan los migrantes durante los primeros años no presentan particularmente condiciones de precariedad habitacional.

\section{Convivencia con población}

no migrante y relaciones de apoyo

En esta sección se analizan las preguntas relacionadas con el apoyo y la participación en organizaciones por parte de los encuestados. Un punto relevante para indagar en la Consulta eran las percepciones sobre el trato y sentimiento de discriminación, así como la interpretación de sus causas.

La población encuestada afirma que su proceso de inserción en Magallanes fue apoyado principalmente por familiares, chilenos y connacionales. Del total de encuestados, 
un porcentaje menor al $10 \%$ afirma no haber recibido ayuda a su arribo a Magallanes. En esta identificación de redes de apoyo se destaca la escasa visibilidad de agentes institucionales, mientras que solo en algunos pocos casos se identifica el trabajo de organizaciones de la sociedad civil. Las redes basadas en vínculos familiares siguen siendo las más importantes.

Por otro lado, una mayoría de participantes afirma que no ha participado en ninguna organización social en Magallanes. La Fig. 13 representa la participación en algún tipo de asociatividad en la ciudad.

Conocer la percepción del trato de los chilenos a los extranjeros en Magallanes fue una de las motivaciones para la realización de la Consulta. El $44 \%$ de los encuestados califica el trato como amable, el $22 \%$ lo considera normal y el $13 \%$ con indiferencia. Se analizó esta pregunta desde las

\begin{tabular}{r|c|} 
No participa & \\
Centro de padres & 16 \\
Otro & 15 \\
Asociación de migrantes & 14 \\
Voluntariado & 10 \\
Grupo religioso & 10 \\
Comité de vivienda & 6 \\
Junta de Vecinos(as) & 6 \\
Sindicato & 6 \\
Club deportivo & 5 \\
Grupo cultural & 4 \\
Cooperativa & 1
\end{tabular}

Fig. 13. Frecuencia de participación en alguna organización social en Magallanes

Fuente: Elaboración propia a partir de Encuesta Consulta Migrante de Magallanes 2015. nacionalidades más representativas. La mayoría de las personas de origen colombiano, argentino y otras nacionalidades declara que los chilenos son amables con los extranjeros $(35,59$ y $46 \%$ respectivamente). Con respecto a los dominicanos, la mayoría afirma ser tratada con normalidad (39\%).

Llama la atención que el $39 \%$ de los encuestados se ha sentido discriminado alguna vez desde que vive en Magallanes(103 personas). La Fig. 14 muestra el sentimiento de discriminación según nacionalidades más comunes. Este sentimiento es mayoría para el caso de los colombianos y dominicanos (56 y $52 \%$ respectivamente), por el contrario, un alto porcentaje de argentinos y otras nacionalidades niega haberse sentido discriminado alguna vez (74 y $71 \%$ respectivamente).

Aquellas personas que se han sentido discriminadas, se subdividieron según sexo. La Fig. 15 muestra que el $100 \%$ de las mujeres dominicanas se ha sentido discriminado. En tres de los cuatro grupos predominan las mujeres como víctimas de discriminación, solo en el caso de los argentinos los hombres afirman haber sido más discriminados que las mujeres ( $56 \%$ hombres y $44 \%$ mujeres).

De todas las personas que se sintieron discriminadas al menos una vez en Magallanes, 57 consultados dicen que lo sintieron o vivieron en un lugar público y 36 personas en el trabajo. 31 personas expresaron haber sido discriminadas en más de un lugar. De las 57 personas que se sintieron discriminadas en lugares públicos, el $46 \%$ es colombiano y el $23 \%$ dominicano. En el caso de los consultados que se sintieron discriminados

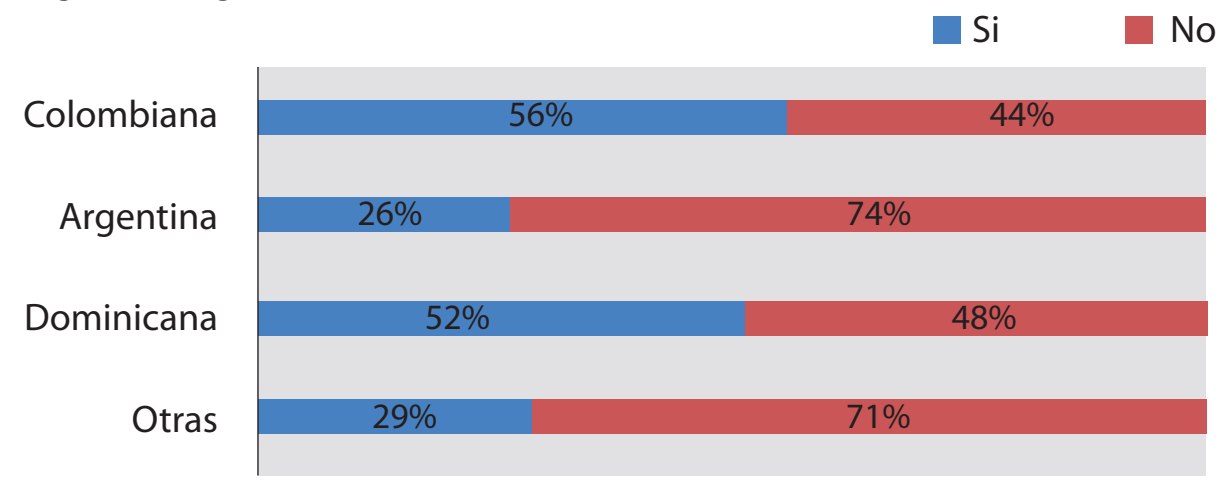

Fig. 14. Nacionalidades más comunes según sentimiento de discriminación

Fuente: Elaboración propia a partir de Encuesta Consulta Migrante de Magallanes 2015. 


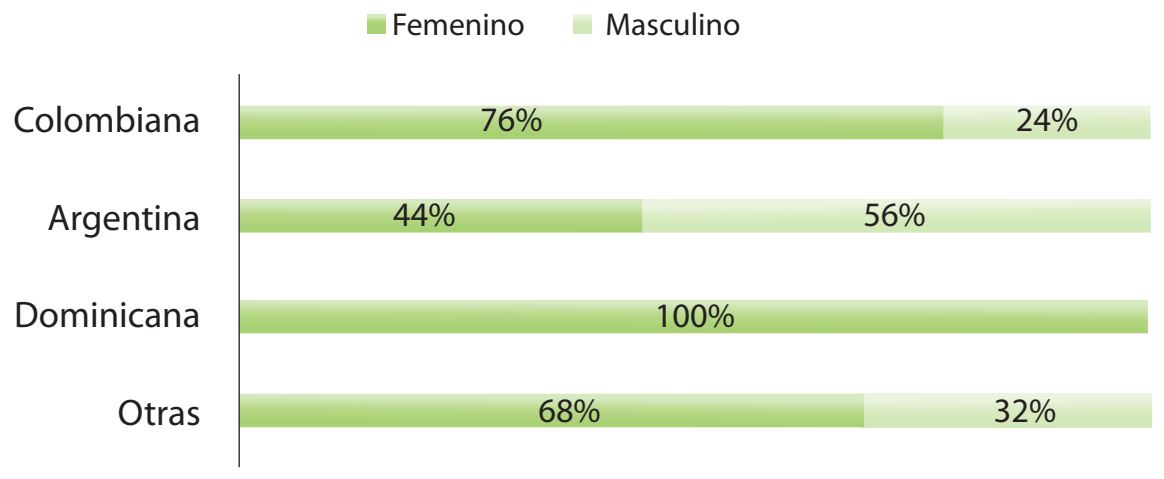

Fig. 15. Sentimiento de discriminación por nacionalidades más comunes según sexo Fuente: Elaboración propia a partir de Encuesta Consulta Migrante de Magallanes 2015.

en el trabajo, el $36 \%$ es de otras nacionalidades y el $31 \%$ colombiano. Respecto a las razones que interpretan como objeto de discriminación, la mayoría afirma que es debido a la "nacionalidad" y $30 \%$ por su color de piel o raza.

Cabe destacar que en el contexto de la aplicación de la encuesta la respuesta a este conjunto de preguntas daba paso a una situación de conversación con los encuestados, quienes relataban los episodios de discriminación de los que referían haber sido víctimas. La mayor parte de estos relatos describe situaciones bastante explícitas de acoso y/o violencia verbal o simbólica, la mayoría de las veces mediada por afirmaciones e insultos abiertamente discriminatorios.

\section{REFLEXIÓN Y DISCUSIÓN SOBRE LAS TRAYECTORIAS MIGRATORIAS EN RELACIÓN A LOS RESULTADOS PRESENTADOS}

La llegada de inmigrantes latinoamericanos a la provincia de Magallanes supone preguntarse por las trayectorias migratorias previas que han determinado el establecimiento y la elección residencial en la ciudad de Punta Arenas como destino final. De acuerdo al ICVU7 2017 Punta Arenas ha sido catalogada como la cuarta ciudad con mejor calidad de vida entre 93 comunas de Chile de un total de 342 , teniendo entre sus atributos sus condiciones laborales, la conectividad y movilidad de la que gozan sus habitantes, y los beneficios de las viviendas y entornos, equipamientos y servicios.

7 ICVU Índice de Calidad de Vida Urbana. Comunas y Ciudades de Chile. Instituto de Estudios urbanos y
No obstante, estas bondades de la ciudad, hay una característica que la hace particular a la hora de estudiar el asentamiento migratorio de los colectivos latinoamericanos, esto refiere a su localización geográfica como una de las ciudades puerto más austral de Chile con un clima templado frío, en que la temperatura media de las máximas es de $9,7^{\circ} \mathrm{C}$ y la temperatura media de las mínimas es de $2,9^{\circ} \mathrm{C}$ (Dirección General de Aeronáutica Civil. Dirección Meteorológica de Chile).

Luken et al. (2011) señala que analizar las trayectorias migratorias suele ser complejo debido al amplio número de itinerarios concretos que experimentan los sujetos migrantes, lo que obliga hacer un esfuerzo para sintetizar las diferentes rutas observadas. El autor propone dos categorías de trayectorias migratorias, las primeras las denomina trayectorias directas entendiendo que una persona ha experimentado este tipo de trayectoria si él/ ella ha vivido tan solo en su país de nacimiento $y$ en el destino migratorio que se estudia, con independencia de si ha vuelto durante algunos periodos a su país de nacimiento. La segunda categoría corresponde a las trayectorias indirectas, que incluirían por tanto todos aquellos itinerarios migratorios en que aparece un tercer país.

Otro aspecto que hay que tener en cuenta en las trayectorias migratorias, son las circunstancias personales y contextuales que influyen en las estrategias de movilidad, por ejemplo, la reagrupación familiar es el más claro exponente de la migración directa, por cuanto la migración

territoriales. PUCCH y Cámara Chilena de la Construcción 
no es un proceso individual, a menudo tiene una dimensión familiar ya que las estrategias y las decisiones de a dónde, cómo y cuándo se migra se efectúan poniendo de relieve a la familia (Luken et al. 2011). Sin embargo, cuando nos referimos a los colectivos de inmigrantes, estos no son homogéneos, por ello se observan itinerarios de trayectorias más complejos entre los que se interrelacionan factores asociados al género, a las trayectorias de sus vidas que son compuestas de distintas etapas, necesidades y proyectos (Agustín, 2002).

En la construcción de trayectorias migratorias sí existe un patrón, el que viene construido por la red de connacionales y no por decisiones individuales que las personas realizan tras informarse de todas las posibles alternativas; esto implica que las trayectorias, aunque aparentemente individuales son trayectorias que siguen recorridos colectivos. Las redes migratorias hacen que a partir de tan solo unos pocos individuos o unas pocas familias se creen amplias comunidades (Garzón, 2007, 2017).

Por ello, uno de los aspectos de mayor peso a la hora de analizar la localización de los colectivos de migrantes en un territorio está dado por la presencia de una red de connacionales. La existencia de connacionales que constituye la red social de referencia para los sujetos migrantes adquiere una real importancia, en tanto se trata con seguridad de uno de los factores explicativos más relevantes del fenómeno migratorio. Es en este punto en que se hace significativa la forma de estructuración que adquieren las redes en particular y el papel que desempeña cada uno de los integrantes en su dinámica, en tanto son ellos quienes establecen canales para la entrada y el asentamiento de los inmigrantes y sus familias (Margarit \& Bijit, 2015).

Estas redes se encuentran, por lo general, constituidas por parientes, amigos y conocidos de familiares. Cabe señalar, comolo hace Pedone (2002), que las redes no son ni espontáneas ni efímeras, cambian y se complejizan con el tiempo debido a las relaciones que genera la entrada de otros actores dentro de su estructura y los modos como circula la información acerca de la inserción en el lugar de llegada, de acceso a la vivienda y al mercado de trabajo. Estas informaciones no son las mismas para todos los sujetos, porque los canales mediante los cuales ellas circulan son las relaciones sociales fuertes que prescinden de la distancia y, por lo tanto, de la frecuencia de los contactos (Ramella, 1995).

En relación con las trayectorias de la población migrante de la región de Magallanes, cabe señalar que el análisis realizado se focaliza después del ingreso a Chile, relacionado con la movilidad que realizan las personas una vez iniciado su proceso migratorio.

En términos generales la población migrante que reside en la región de Magallanes no presenta mucha movilidad al interior de Chile, más del $80 \%$ de los encuestados señala que ha estado en una sola ciudad del país, siendo el destino principal Punta Arenas. En este sentido, podemos establecer que existen trayectorias migratorias de tipo directo en la línea que propone Luken et al (2011), es decir, que su primer destino es la ciudad de Punta Arenas en la que se encuentran al momento del estudio.

La Fig. 16 se expone con más detalle el perfil de quienes presentan trayectorias indirectas, es decir, quienes han pasado por 2 o más ciudades chilenas antes de asentarse en Magallanes. De este conjunto, los ciudadanos argentinos residieron en alguna ciudad del sur del país, mientras que un porcentaje menor también lo hizo en ciudades del norte, especialmente colombianos y dominicanos. También destaca un porcentaje mayor de mujeres (57\%) que de hombres quienes presentan trayectorias indirectas.

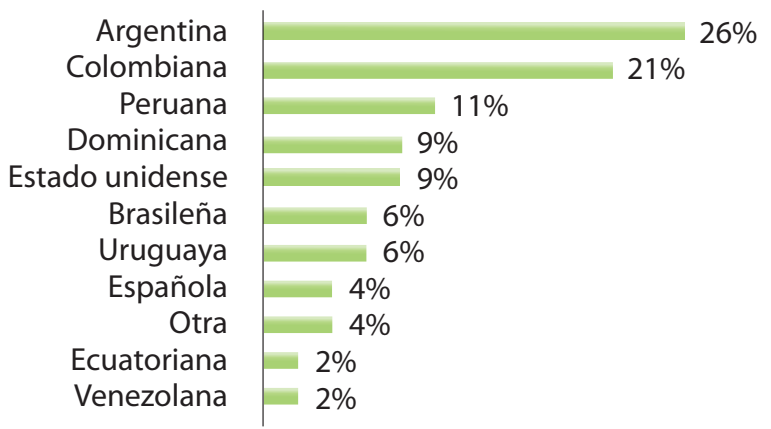

Fig. 16. Residencias en más de una ciudad en Chile antes de residencia en Punta Arenas por nacionalidad

Fuente: Elaboración propia a partir de Encuesta Consulta Migrante de Magallanes 2015. 
Sobre el tiempo que llevan en Chile, en general se puede establecer que es una población migratoria no reciente, pues la mitad de los encuestados lleva más de 8 años en el país $(50 \%$ de los encuestados). Esto en parte podría explicar la migración entre ciudades, pues habría más posibilidades de cambiarse de ciudad cuando el periodo de migración es más extenso.

Sobre los motivos por los cuales se migró del país de origen, en términos generales la mayoría de los encuestados señala que la razón principal fue el trabajo; sin embargo, al disgregar los resultados por nacionalidad podemos observar que existen ciertas diferencias. Los participantes de nacionalidad argentina vienen a Chile principalmente por motivos de trabajo, pero también por reunificación familiar, los participantes de nacionalidad colombiana en su mayoría llegaron a Chile de paso o turismo, mientras que los peruanos lo hacen principalmente por reunificación familiar.

Sobre su situación ocupacional actual, una considerable y amplia mayoría de los encuestados (90\%) señala que está actualmente ocupado; sin embargo, no todos ellos señalan tener contrato. De quienes están actualmente ocupados, un $27 \%$ indica no tener contrato. Entrando más en detalle sobre la actividad laboral, se preguntó sobre el sector en el cual se desempeñaban en la actualidad. La mayoría de los participantes trabaja en el sector de los servicios, principalmente en el área del comercio, siendo los encuestados de nacionalidad argentina y peruana quienes tienen más representación en esta área.

Finalmente, se interrogó a los participantes sobre la manera en que encontraron trabajo en Magallanes. Las dos respuestas más nombradas son quienes conocían el mercado laboral y tenían conocimientos sobre las oportunidades que podían alcanzar; no obstante, en un mismo porcentaje $(31,7 \%)$, hay quienes llegaron a Magallanes sin saber nada sobre el mercado laboral chileno. También es interesante mencionar que un porcentaje no menor (22\%) llegó a Magallanes con un contrato de trabajo, tal como se presenta en la Fig. 17.

\section{CONCLUSIONES, DESAFÍOS Y REFLEXIONES FINALES}

Las principales características de los participantes del estudio se sintetizan a continuación. Fueron consultadas personas de sexo femenino mayoritariamente. Las nacionalidades con mayor predominancia en la Consulta fueron colombiana, argentina y dominicana, en concordancia con las nuevas tendencias migratorias de la región. El promedio de edad de los encuestados fue de 34 años, se presenta una concentración de ciudadanos colombianos y dominicanos bordeando los 30 años, a diferencia de argentinos que presentaron mayor edad. En cuanto a la escolaridad, los participantes de origen argentino tienen en promedio más años de escolaridad relativa, en general se trata de una población con altos niveles de educación formal.

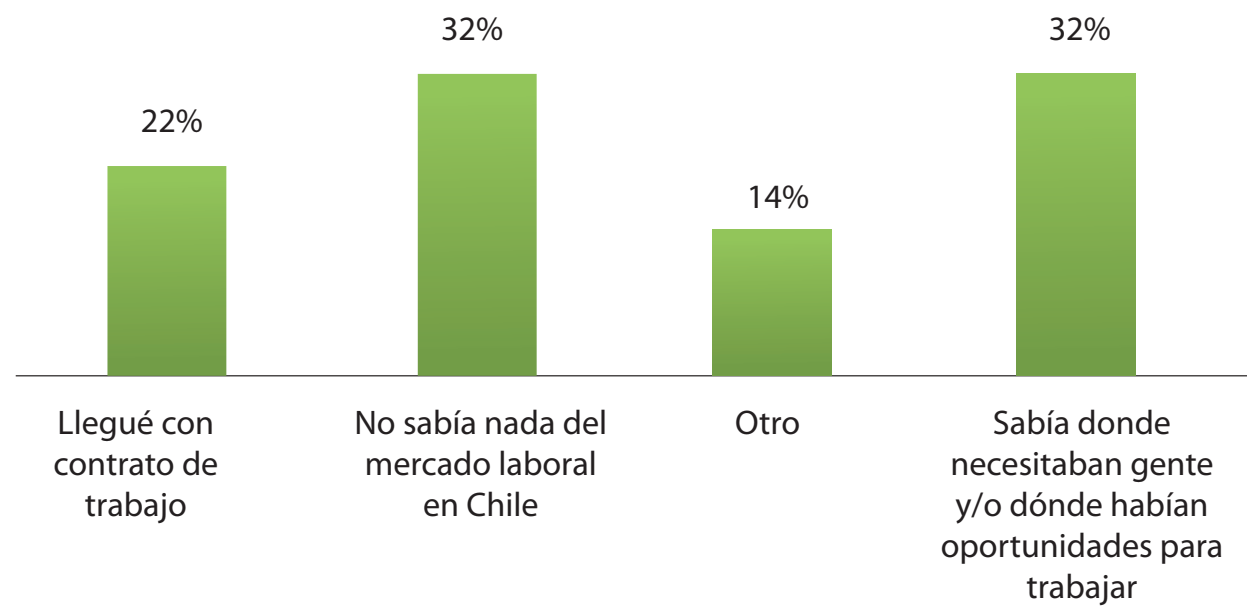

Fig. 17. Manera en que encontró trabajo

Fuente: Elaboración propia a partir de Encuesta Consulta Migrante de Magallanes 2015. 
Las personas de nacionalidad dominicana provienen principalmente de dos ciudades: Santiago de los Caballeros y San Cristóbal. Existe un importante número de personas de nacionalidad colombiana que llega principalmente del Valle del Cauca. Por otro lado, las personas de nacionalidad argentina provienen de diferentes ciudades $y$ regiones del país. Es conocido que en Magallanes existe un importante contingente de población argentina original de la Patagonia, esta población suele no autoidentificarse como migrante en virtud de sus relaciones históricas con la Patagonia chilena.

La espacialización de la población migrante en Punta Arenas se despliega por distintos barrios de la ciudad, lo que permite el encuentro cotidiano entre migrantes y no migrantes. Una reflexión específica de esta forma de espacialización requiere de un análisis respecto a los mercados de vivienda y conformación de los barrios de la ciudad que expliquen esta distribución, la cual puede ser considerada como positiva en cuanto puede apoyar procesos de inserción de la población migrante con la población local.

Ciudadanos dominicanos y colombianos son las poblaciones de más reciente arribo a la Provincia. Existen diversos motivos por los que llegaron a Magallanes, la mayoría lo hizo por temas relacionados al trabajo, siendo también significativas razones de reunificación familiar y vínculos afectivos.

Se puede concluir que los consultados presentan una situación migratoria regular. Los colombianos son los que más tienen visas temporarias por vínculo o sujeta a contrato y los argentinos encuestados tienen en mayor número visa de turismo.

En cuanto al vínculo de migrantes con su país de origen, se analiza que la manera más cotidiana de comunicarse es mediante las redes sociales. Existe un vínculo permanente con el país de origen, tanto en el intercambio de información como en el envío de remesas.

Por otro lado, en el ámbito de la familia existe un alto porcentaje de parejas binacionales (chilenas-extranjeras), lo cual puede facilitar la inserción en la sociedad magallánica. Los hijos menores de edad pueden aspirar mayormente a la reunificación familiar.
Llama la atención la baja participación en organizaciones, iniciativas o formas asociativas por parte de los consultados. En cuanto al trato de los chilenos hacia la población migrante, existen altos porcentajes al sumar "desconfianza" y "desprecio", dos atributos negativos de este aspecto. Al consultar por el sentimiento de discriminación que han sentido, en tres de los cuatro grupos predominan las mujeres que se han sentido discriminadas, asociado al origen afrodescendiente.

En un análisis más interpretativo de los datos se pueden establecer tres ideas centrales:

- La población inmigrante accede principalmente al mercado del trabajo a través de mecanismos formales. No se identificó con un peso relevante la formación de "economías étnicas" sustentadas por redes de apoyo, cuya participación está mediada por la adscripción a una nacionalidad o redes de familiares y amigos. La población migrante participa principalmente del mercado del trabajo de Magallanes como cualquier otro habitante de la Provincia. De igual modo, no se identificaron situaciones masivas de vulneración de derechos o de acceso restringido a servicios como salud y educación.

- La convivencia entre la población inmigrante y los habitantes tradicionales de Magallanes puede ser vista como una dimensión sensible en el contexto de la actual migración. Situaciones de discriminación abierta han sido experimentadas por muchos de los nuevos habitantes de Magallanes, especialmente como ya lo planteamos, mujeres afrodescendientes. Estereotipos y prejuicios asociados a la población migrante se encuentran en la base de estas acciones, que si bien se identifican como no generalizadas ni masivas, han afectado a un buen porcentaje de los encuestados.

- La conectividad que permite las redes sociales comunica de forma cotidiana a la población migrante con sus lugares de origen y sus habitantes. Este flujo de información dinamiza los movimientos de poblaciones hacia Magallanes. La población migrante se encuentra fuertemente conectada 
con las dinámicas del mercado del trabajo local, así como con la información que permite el acceso a vivienda y otros servicios.

Por último, a partir del análisis de las trayectorias migratorias se puede reflexionar, en primer lugar, acerca de comprender la migración no como una agregación de decisiones individuales (Sassen, 2013), sino como la construcción de comunidades de migrantes que presentan tendencias de movilidad de acuerdo a las temporalidades de sus proyectos migratorios, tensionando las estructuras sociales, económicas y políticas de los territorios en donde se localizan. En este punto está el desafío para la política pública de dar respuestas oportunas a todos los habitantes de sus territorios garantizando derechos.

En segundo lugar, el análisis interpretativo de las trayectorias de las migraciones nos otorga una constatación de la naturaleza diferenciada de la inmigración $y$ en particular de la migración circular y el asentamiento permanente (Sassen, 2013). Los actuales patrones de movilidad de las migraciones no son solo de frontera, sino que explican la movilidad que tienen los migrantes en el país y su alto dinamismo en la conexión con los lugares de origen, no representando una ruptura drástica con el país natal como antes de la segunda mitad del siglo XX (Newland, 2006).

Para finalizar, es necesario reflexionar acerca de la relación entre trayectoria migratoria y la conFig.ción de identidades múltiples que cambian y que se relacionan con experiencias de des- y re-territorialización. Estas experiencias de la población migrante vinculan a las poblaciones locales, también transformando los sentidos de lo que significa el ser magallánico.

\section{AGRADECIMIENTOS}

Estudio financiado por el Ministerio del Interior, Gobernación de Magallanes en el marco del programa de Modernización del Estado.

La realización de este artículo se enmarca en el desarrollo del Núcleo Milenio Movilidades y Territorios MOVYT de la Iniciativa Milenio del Ministerio de Economía, y al apoyo de DICYT
Universidad de Santiago de Chile, USACH.

Agradecemos al equipo de investigación compuesto por Consuelo González P., Eduardo Osterling y Florencia Grau.

\section{BIBLIOGRAFÍA}

Agustín, L. M. (2002). Cuestionar el concepto del "lugar": La migración es algo más que una pérdida. En Development. Society for International Development, 45. Roma.

Angelo, G. (2015). Historias de mujeres inmigrantes en Magallanes. Santiago de Chile: Ediciones Radio Universidad de Chile.

Barelli, A. I., \& Dreidemie, P. (2015). Migraciones en la Patagonia. Subjetividades, diversidad y territorialización. Viedma: Universidad Nacional de Río Negro.

Cid, C., \& Leiva, F. (2008). La presencia y evolución en el tiempo de la inmigración española en la Comuna de Punta Arenas, desde 1843 hasta nuestros días; instituciones, costumbres y tradiciones. Universidad de Magallanes.

Contreras, Y., \& Palma, P. (2015). Migración latinoamericana en el área central de Iquique. Nuevos frentes de localización residencial y formas desiguales de acceso a la vivienda. Anales de Geografía de La Universidad Complutense, 35(2), 45-64.

Contreras, Y., Tapia, M., \& Liberona, N. (2017). Movilidades y prácticas socioespaciales fronterizas entre Arica y Tacna. Del sentido frontera a la transfrontericidad entre ciudades. Diálogo Andino, 54, 127-141.

Dirección General de Aeronáutica Civil. Dirección Meteorológica de Chile. http://www.meteochile.gob.cl/PortalDMCweb/index.xhtml

Ducci, M. E., \& Rojas, L. (2010). La pequeña Lima: Nueva cara y vitalidad para el centro de Santiago de Chile. EURE (Santiago), 36(108), 95-121.

Garcés, A. (2012). Localizaciones para una espacialidad: territorios de la migración peruana en Santiago de Chile. Chuagará, 44(1), 163-175.

Garcés, A. (2015). Migración Peruana en Santiago. Prácticas, espacios y economías. Santiago de Chile: RIL Editores.

Garzón, L. (2007). Trayectorias e integración de la Inmigración argentina y ecuatoriana en Barcelona y Milano. Tesis doctoral. Universidad Autónoma de Barcelona, España.

Garzón, L. (2017). ¿Declive de la ciudad multicultural? Entre2orillas. Revista transnacional para la convivencia intercultural, 12, 12-14.

Guizardi, M. (2016). El (des)control del "yo": frontera y simultaneidad en una etnografía sobre las migrantes peruanas en Arica (Chile). Estudios Atacameños, 53, 159-184.

ICVU Índice de Calidad de Vida Urbana. (2017). Comunas y Ciudades de Chile. Instituto de Estudios urbanos y territoriales. PUCCH y Cámara Chilena de la 
Construcción. Santiago, Chile.

Imilan, W., Márquez, F., \& Stefoni, C. (2016). Rutas migrantes en Chile: Habitar, festejar y trabajar. Ediciones Universidad Alberto Hurtado. Santiago. Chile.

Instituto Nacional de Estadísticas. INE. (2019). Estimación de Personas Extranjeras Residentes en Chile. INE y Departamento de Extranjería. Chile. Rescatado de www.ine.cl

Instituto Nacional de Estadísticas. INE. (2018). Características de la inmigración internacional en Chile, Censo 2017. Departamento de Demografía y Censos. Rescatado de www.ine.cl

Instituto Nacional de Estadísticas. INE. (2018). Síntesis de Resultados Censo 2017. Rescatado de www.ine.cl

International Organization for Migration. IOM. (2018). World Migration Report 2018. Switzerland. https://www. iom.int/wmr/world-migration-report-2018

Irazábal, C. (2013). Transbordering Latin Americas: Liminal Places, Cultures, and Powers (T)Here. NYC: Routledge.

Levitt, P., \& Glick Schiller, N. (2004). Conceptualizing Simultanety: A Transnational Social Field Perspective on Society. International Migration Review, 38(145), 595-629.

Liberona, N., Tapia, M., \& Contreras, Y. (2017). Movilidad por salud entre Arica y Tacna: análisis de una demanda no satisfecha y de una oferta atractiva del otro lado de la frontera, Geopolítica(s). Revista de estudios sobre espacio y poder, 8(2), 253-278.

Luken, M., Solana, M., \& Pascual de Sans, A. (2011). La trayectoria migratoria internacional de la población inmigrada en España: la incidencia de las redes familiares y otras características sociodemográficas. Scripta Nova. Revista Electrónica de Geografía y Ciencias Sociales, XV, 357

Margarit, D., \& Bijit, K. (2014). Barrios y población inmigrantes: El caso de la comuna de Santiago. Revista INVI, 29(81).

Margarit, D., \& Bijit, K. (2015). Los Negocios de Inmigrantes Sudamericanos: Una Aproximación a las Estrategias de Instalación e Integración Socioterritorial en la Comuna de Santiago de Chile. En M. Lube Guizardi (Ed.), Las fronteras del transnacionalismo: limites y desbordes de la experiencia migrante en el centro y norte de Chile (pp. 63-83). Santiago de Chile: Ocho Libros Editores.

Martinic, M. (1999). La inmigración croata en Magallanes. Punta Arenas: Impresos Vanic.

Matossian, B. (2015). División social del espacio residencial y migraciones: El caso de San Carlos de Bariloche, Argentina. EURE (Santiago), 41(124), 163-184.

Micheletti, S. (2016). Inmigración en la ciudad intermedia agraria: El caso de Talca- Chile. Rumbos, 11(14), 1128.

Morse, J. (2003). Principles of mixed methods and multimethods research design. En C. Teddlie \& A. Tashakkori, Handbook of mixed methods in social and behavioral research. London: Sage.
Newland, K. (2006). Las redes migratorias como recurso del desarrollo más allá de las remesas. En C. Blanco (Ed.), Migraciones. Nuevas movilidades en un mundo en movimiento ( $p$. 57-90). Barcelona: Editorial Anthopos.

Observatorio Social, Ministerio de Desarrollo Social (2016). Encuesta de Caracterización Socioeconómica CASEN 2015. Santiago, Chile.

Observatorio Social, Ministerio de Desarrollo Social (2018). Encuesta de Caracterización Socioeconómica CASEN 2017. Santiago, Chile.

Organización Internacional para las Migraciones. OIM (2003). Las migraciones Internacionales: análisis y perspectivas para una Politica Migratoria. Ginebra, Suiza.

Organización Internacional para las Migraciones. OIM (2014). La Migración Sur-Sur: Asociarse de Manera Estratégica en pos del Desarrollo. En No. 23 Diálogo Internacional Sobre la Migración. Ginebra, Suiza.

Park, R. E. (1999). La Ciudad y otros ensayos de ecología urbana. La Estrella Polar, 18, 7-141.

Pedone, C. (2002). El potencial del análisis de las cadenas y redes migratorias en las migraciones internacionales contemporáneas. En F. García, C. López (Eds.). Actas del III Congreso sobre la inmigración en España (pp. 223-235). Contextos y alternativas. Granada: Laboratorio de Estudios Interculturales.

Ramella, F. (1995). Por un uso fuerte del concepto red en los estudios migratorios (9-21). En Bjerg, M. \& H. Otero (Comps.), Inmigración y redes sociales en la Argentina Moderna. Buenos Aires: CEMLA-IEHS.

Sassen, S. (2013). Inmigrantes y ciudadanos. De las Migraciones Masivas a la Europa Fortaleza. España: Editorial Siglo XXI.

Stefoni, C. (2011). Perfil Migratorio de Chile. Organización Internacional para las Migraciones (OIM).

Tapia, M. (2017). Las fronteras, la movilidad y lo transfronterizo: Reflexiones para un debate. Estudios Fronterizos, 18(37), 61-80.

Tapia, M., \& González, A (Eds.). (2014). Regiones transfronterizas. Migración y los desafíos para los Estados nacionales latinoamericanos. Santiago de Chile: RIL.

Tapia, M., Liberona, N., \& Contreras, Y. (2017). El surgimiento de un territorio circulatorio en la frontera chilenoperuana: estudio de las prácticas socio-espaciales fronterizas. Geografía Norte Grande, 66, 117-141.

Tezanos, J. F. (2006). La cuestión migratoria en España. Sistema, Número 190-191. Dedicado a: Inmigración y exclusión social. España.

Thayer, L. (2016). Migración, Estado y seguridad: Tensiones no resueltas y paradojas persistentes. Polis, Ago, 15(44), 109-129

Whyte, W. F. (1943). Street corner society. The social structure of an italiens slum. Chicago: University Chicago Press. 